\title{
Meaningful patient engagement
}

\section{Clare Gerada}

\begin{abstract}
SUMMARY
Holding a medical degree does not magically protect the individual from ever becoming unwell or needing medical help. However, for various reasons, most of which relate to personal, professional and institutional stigma, doctors are often denied the care they so readily provide to their own patients. The author has been running a 'sick doctor' service for 10 years and this article describes, from the practitioner-patient perspective, the barriers to care and what can be done to improve doctors' access to services.
\end{abstract}

\section{LEARNING OBJECTIVES}

- Appreciate the external and internal risk factors for mental illness in doctors

- Understand why doctors do not attend for care when mentally unwell

- Acknowledge how mentally ill doctors are exposed to stigma and how this can be overcome

\section{DECLARATION OF INTEREST}

C.G. is a partner of the Hurley Group who won the contract for PHP in 2008 and is employed by and leads the NHS Practitioner Health Programme.

This article draws on my experience of being a doctors' doctor, for the past decade leading the NHS Practitioner Health Programme (www.php. nhs.uk), a confidential service for doctors and dentists with mental health and/or addiction problems. It is about doctors and how their voices can be heard when they cross the divide and become practitioner-patients. By focusing on the medical profession, this is not to underestimate or ignore the problems of other hard-working health professionals, many of whom experience the same levels of stigma and lack of attention as doctors. Doctors' voices, however, are some of the most silent among the patient population. This article endeavours to explain why.

I use the term 'practitioner-patient' to describe a doctor who has become a patient and 'sick doctor' to refer to a doctor who is unwell and has not yet presented for care.

\section{Doctors and mental illness}

Compared with the general population and other professional groups, doctors have high rates of mental illness. There is considerable evidence from a number of studies that, across all healthcare systems, specialties, ages and genders, doctors have a higher rate of mental illness than an aged matched population and up to three times the rate of suicide (Brooks 2011). This might at first seem odd, given the many protective factors that doctors have - for example, above-average intelligence, high income relative to the average population, a rewarding career, high status and a job that provides financial and career stability. However, they are of course just as exposed to life events such as loss, illness and family discourse as other individuals and have no more immunity to early traumatic events that predispose them to later mental illness. There are also risk factors inherent in their profession which are unique (or almost), place them at increased risk of becoming unwell and, once unwell, prevent them from seeking appropriate and timely help. These are most easily thought of as the combination of the working environment (occupational factors), what doctors themselves bring to the table - that is, their own personality and psychological vulnerabilities - and the pressures placed on them by patients and the public.

\section{Reasons why doctors become mentally unwell}

There can be few occupations that face the intense stresses experienced in the daily practice of working in healthcare. Ballatt \& Campling, the authors of Intelligent Kindness, remind us that it is easy to forget the appalling nature of some of the jobs carried out by NHS staff day in, day out the damage, the pain, the mess they encounter, the sheer stench of diseased human flesh and its waste products' (Ballatt 2011: p. 53). Nurses and doctors have a heavy and unrelenting workload, performing unsung small acts of heroism on a daily basis and sacrificing their own needs for their patients.

Doctors work in a system with high social and political pressure not to fail and, when they or their organisation do fall below the ideal standard, the reaction is so often to name, shame and blame. The culture of litigation, where every death appears to be a failure in the system rather than a natural conclusion to life, adds pressure and additional fear to doctors' already difficult role. All of this places a heavy psychological burden on the individual (Lelliott 2008). Doctors are also exposed to,
Clare Gerada is the Medical Director of the NHS General Practitioner Health Service and has been a General Practitioner at Hurley Group, London, UK since 1992.

Correspondence Clare Gerada, Practitioner Health Service, Hobart House, St George Wharf, Wandsworth Road, London SW8 2JB, UK. E-mail: clare.gerada@nhs.net

Copyright and usage (C) The Royal College of Psychiatrists 2018 
and trained to use, dangerous drugs. Among these, potent anaesthetics and strong analgesics are particularly important, as those working in emergency specialties (anaesthetists, interventionists, and accident and emergency doctors) have proportionally high rates of suicide.

Doctors bring their own vulnerabilities to the job. They are chosen for personality traits that predict good doctoring. Most have a good measure of perfectionism ('I must do this right - mistakes are intolerable'), narcissism ('I am the greatest'), obsessiveness ('I must do this and I can't give up till I finish'), shame ('People who need help are failures. If I need help, I'm a failure') and martyrdom ('I care for my patients more than myself and my needs are secondary to those of the people I treat') (Adshead 2010). In times of stress these personality characteristics can become exaggerated, leading to overwork and burnout. Added to these is the unhelpful cognitive triad, developed during training, of doubt, guilt and an exaggerated sense of responsibility (Gabbard 1985). To survive a lifetime in medicine, doctors develop psychological defences such as depersonalisation and denial of feeling (MenziesLyth 1959). These create an armour of detachment which helps overcome fear, disgust and anxiety. But while such armour may serve as a protection, this security is bought at the price of inaccessibility and emotional distancing. It comes as no surprise that doctors have high rates of divorce, especially psychiatrists and surgeons, who have to develop additional layers of defence to survive their job. Furthermore, defences can be, and indeed are, exploited and turned against the doctor, for example when they are asked to work harder and deliver more without additional resources. Without a safety net or a safe space to vent their frustration it can be displaced onto themselves (as, for example, drug or alcohol misuse, burnout or depression), onto colleagues (as bullying or aggression) or even onto patients (as doctors might cross boundaries to try to protect patients from the inadequacies of the system, e.g. shouting or being rude to a patient, or texting a patient in an inappropriate manner).

\section{Why are doctors infrequent users of healthcare services?}

Despite higher rates of mental illness, doctors are low users of mental health services: they suffer in silence or, in extreme cases, take their own lives rather than seek the care they so readily prescribe to their patients (Brooks 2011). They are some of the most unattended patients in our community. Doctors find it very difficult to take off their metaphorical white coat and replace it with the patient's gown. The reason is multifactorial (Box 1), but
B0X 1 Structural and professional barriers preventing doctors from seeking help

- Personal, professional and structural barriers to disclosure

- Denial and psychological barriers (e.g. illness = failure)

- Difficulties with disclosure, especially where mental illness involves drugs/alcohol

- Fears for career progression

- Professional and personal stigma

- Fears of discrimination if vulnerability is admitted

- Frequent moves preventing registration or continuity of care if engaged in treatment

mostly it relates to denial of illness, a denial that runs deep. Among doctors, presenteeism - coming into work when unwell - is more of a problem than absenteeism (Wrate 1999). Doctors will come into work with physical or mental health problems, in part driven by the guilt of knowing that, if they do not, someone will have to cover their shift. When doctors do seek care they often have so-called "corridor conversations' - receiving snippets of care outside the normal consulting room - or they seek informal advice from friends or family rather than risk the humiliation of taking on the patient role.

\section{Stigma as a barrier to treatment}

Patients with mental illness have more to deal with than just the illness itself. Despite efforts to reduce it, stigma is endemic in the mental health environment and has a strong effect on individuals' willingness to seek treatment, owing to feelings of anxiety, fear and shame (Dinos 2004). This is probably more so among doctors than the general population. Doctors are subjected to stigma at every turn: individual (internalised fear of disclosure of mental illness), collective (among doctors as a group) and institutionalised (from the public, policy makers and other professionals) (Box 2). There is always

\section{BOX 2 Problems associated with doctors becoming patients}

- Isolation and embarrassment at loss of role

- Loss of power and tools of power (e.g. the ability to prescribe or to refer patients)

- Challenge to the medical self and having to assume the most conflicted of all identities, that of patienthood: changing the white coat for the patient's robe 
the risk that disclosure of mental illness will lead to loss of livelihood and/or career, resulting in further humiliation and disgrace (Hinshaw 2008).

\section{Personal stigma}

The long and gruelling training required to become a doctor does more than give each student the knowledge they need to do their job; it also prepares them for this life of self-sacrifice. As part of the hidden curriculum, doctors are trained to ignore their own needs. This is embodied in the duties of a doctor, with the General Medical Council (2013) demanding 'Make the care of your patient your first concern'. As medical students train, two distinct transformations occur which change their sense of who they are (their identity) and their sense of belonging (in that they form a strong attachment to the medical profession) (Klitzman 2008). These changes happen unconsciously and, once complete, allow doctors to do the jobs society demands of them, but they also act as barriers to taking on the patient role - as the unwritten rules of the medical self, contained within the 'group of belonging', preclude doctors from becoming unwell (Wessely 2013).

Paradoxically, sick doctors become more entrenched in their medical self and their group, as they throw themselves into work, take on extra hours and see more patients. This reaction becomes akin to magical thinking or manic defence, as the account of one doctor who was suffering from depression yet continuing to work makes clear: 'I thought that if I work harder, I can't be ill, so I got in earlier and earlier to work, saw more and more patients. But in the end it all fell apart when I crashed the car on the way to work'.

Henderson et al (2012) interviewed doctors who were not working due to mental illness. These doctors described that being away from work left them isolated and sad. Self-stigmatisation was central to the participants' accounts; several described themselves as failures and appeared to have internalised the negative views of others. The authors concluded that these views, which possibly emerge from the belief that 'doctors are invincible', represent a major obstacle to doctors returning to work.

\section{Professional stigma}

Once unwell, sick doctors are treated differently by their own peers. Sick doctors and practitionerpatients face high levels of professional stigma from other doctors. The doctors interviewed as part of Henderson et al's study (2012) experienced negative reactions from other doctors and some deliberately concealed their problems. They also described a lack of support from colleagues and feared a negative response when returning to work.
At the collective level, the medical profession unconsciously holds to a notion that doctors should not be ill. This is perhaps most evidenced by doctors not recognising illness or signs of distress in other doctors. They appear to be blind not only to their own distress but also to that of other members of their community. For example, doctors miss obvious telltale signs of a colleague in distress such as red eyes, weight loss, tearfulness or even needle track marks - which would have been identified were it not for the title 'Dr'.

When a doctor does become a patient and consults with a fellow health professional they are also treated differently. Many doctors feel uncomfortable seeing sick peers, and consultations are difficult, especially where mental health is concerned. Often the doctor they are seeing treats them more as a colleague than a patient, sometimes even going as far as to suggest that the sick doctor treats, or at the very least knows how to treat, themselves and even organises their own investigations. This is most common when the doctor they are seeing is from the same specialty. The implication is that the only patient role allowed is that of an expert-patient, rather than the vulnerable, frightened individual many are when unwell.

In the UK, doctors are often confused as to whether they need to report a practitioner-patient to the General Medical Council when the practitioner presents with a mental illness. Overall, the requirement to disclose is only where there are risks to other patients or where the doctor is engaging in an illegal activity (such as taking illicit drugs). Having depression, bipolar disorder, psychotic illness, alcohol dependence or even being detained under the Mental Health Act are not automatic grounds for disclosure.

When doctors do get into a consulting room as patients they visibly try to regain the control of their medical self, by repeatedly 'talking shop' (for example, discussing the latest research into their own condition). Clinicians at the NHS Practitioner Health Programme essentially ban 'shared decision-making' until the mental state of the practitioner-patient improves.

\section{Institutionalised stigma}

Stigma among mentally ill doctors is also institutionalised. Patients have a vested interest in doctors not becoming unwell, beyond the obvious of creating waiting lists or having cancelled operations. The sociologist Talcott Parsons (Parsons 1951) described the sick patient in theoretical terms as having certain roles and responsibilities achieved through maintenance of a paternalistic stance on the part of the doctor and rigid boundaries 
between the roles of the doctor and the patient. These roles act to maintain the tacit contract between patient and doctor: patients become unwell, not doctors. Furthermore, when the latter do become unwell, there is a conscious and unconscious requirement that they keep their illness from public sight. Both patients and doctors enter unconscious symbiotic processes. Thomas Main, in discussing the therapeutic community, a term that he coined, described the defensive interplay of projections between caregivers and patients and the "phantastic' collusion that occurs between the two:

'[The] helpful will unconsciously require others to be helpless while the helpless will require others to be helpful. Staff and patients are thus inevitably to some extent creatures of each other' (Main 1975: p. 61).

\section{Treating doctors}

The NHS Practitioner Health Programme has been collecting the experiences of practitioner-patients for nearly a decade and some of these experiences are published on its website (http://php.nhs.uk/ patient-stories). PHP is now the largest treatment service in Europe for sick doctors and it delivers comprehensive, integrated mental health services to doctors and dentists across England. It provides expertise at the interface between the profession and the practitioner-patient, supporting doctors through their treatment and back to work or training. Individuals from all medical specialties have presented to the service, their age ranging from newly qualified to recently retired. Around twothirds of the patients have mental health problems, mostly anxiety, depression and symptoms indistinguishable from post-traumatic stress disorder. Around one-third have problems related to dependence, mostly alcohol, although this category includes drug misuse, gambling and other addictions. Since the PHP was set up in 2008, nearly 100 patients have presented with bipolar disorder, over 250 with addiction disorder, and we have identified patients with undiagnosed schizophrenia and personality disorder. Doctors attending PHP get better. Repeated analyses, including a prospective study of the outcomes of 200 consecutive patients (Brooks 2013), have shown this.

Improvements are found in all areas of functioning, including return to work and/or training, mental health and well-being, and social functioning (Brooks 2013). A study of practitioner-patients with substance use problems found that $80 \%$ became abstinent after treatment and only 6\% relapsed to problematic use: if the doctor was abstinent by 6 months, abstinence was likely to be long term (details available from C.G. on request). Engagement in treatment can therefore provide reassurance to regulators, employers and training institutions. Practitioner-patients appreciate that PHP understands their unique experience and that they feel attended to and cared for.

\section{Doctors in groups}

The PHP offers support and psychotherapy groups to practitioner-patients. Group therapy can help health professionals renegotiate their professional identity. A theme permeating doctors' groups is the reassurance of knowing that they are not alone. This is especially important where the doctor has been excluded from their work environment either through suspension or removal from the medical register. The therapy group provides a mirror to gain relief from the experience of others. A doctors-only group offers a secure base, allowing doctors to drop their mask of empathy and become patients. Despite initial reluctance, once engaged doctors are good at using groups to effect therapeutic change and have remarkably good outcomes (Gerada 2016). United through their profession, doctors are able to talk to each other with powerful authenticity without the need to explain and without feeling (implicitly or explicitly) attacked.

\section{Asking doctors their views: 'All we need is compassion'}

During a qualitative study in which interviews with practitioner-patients of PHP were conducted, doctors reported feeling happier, more relaxed, more self-confident and emotionally stronger; several felt they had rebuilt their self-respect; and many had improved their relationships with family members and colleagues (Brooks 2017). The researcher reported that an unexpectedly large number credited PHP not only with having a significant impact, but with saving them, their careers and even their lives. One said that finding PHP had led them to '[abandon] the idea of committing suicide'. This study confirmed what the literature has repeatedly told us: that, not surprisingly, although some of the needs of mentally unwell doctors mirror the needs of patients in general - e.g. a supportive and non-judgemental attitude from clinicians - they do have specific needs related to confidentiality and stigma. These practitioner-patients highlighted the many barriers that doctors have when trying to seek confidential help and become patients. Even knowing where to go when unwell can be difficult. An overwhelming issue was that of wishing to receive compassionate, non-judgemental care and doctors yearned for the same degree of compassion that they give to their own patients. 'Compassion', encompassing care for well-being, sensitivity, sympathy, distress tolerance, empathy and non- 
judgement, is as important for doctors as for any other patient. Doctor after doctor expressed how important it was that their treating clinicians understood the specific needs of a practitioner-patient and the experiences unique to the health profession which they may need support with. These experiences were almost all related to the sense of exclusion (from medical self, group of belonging, friendship and professional network) when unwell.

\section{The practitioner-patient's voice}

Given that it is hard for doctors to seek help and how secretive they can be when doing so, it is important that their collective and individual voices are heard as, without this, services may continue to make it very difficult for doctors to become patients by putting up conscious and unconscious barriers.

In the first instance, listening to the practitionerpatient voice would ensure that they can choose confidential care, ideally outside their own working environment, which is especially important if they have mental health problems (Box 3).

\section{The personal risks and community benefits of sharing experiences}

Even if their mental illness does not fall outside of the GMC's guidance on good medical practice, there are problems which may result from doctors telling their story outside a confidential consulting room. They can face sanctions if they share their experience of illness, as in the case of Dr Potts, a GP who kept a blog about living with bipolar disorder. Reports were that she was referred to the GMC following a complaint that she had described her own experience during a consultation with a patient. Sadly, Dr Potts killed herself and press coverage implied that her suicide was directly linked to her disclosure (Parveen 2016). Fortunately, this tragic case is the exception, not

BOX 3 'Self-referral': the story of one essentially fictional practitioner-patient

Peter was a consultant in liaison psychiatry in a large mental health trust. He realised that he had become more and more depressed since finding out that his wife was having an affair. He attended his general practitioner (GP), who prescribed antidepressants and referred him to the local behavioural therapy service. One month later, during the multidisciplinary referral team meeting, Peter began to read out a referral from a local GP. He stopped suddenly, realising that he was reading out his own referral. He had been referred to himself.

After this unpleasant experience, Peter became a patient of the Practitioner Health Programme. the norm and the practitioner-patient's individual voice is heard in blogs, testimonies and via social media.

For decades, practitioner-patients' voices have also been heard directly through first-person narratives in journals and mainstream media. The $B M J$ used to publish regular first-person narratives by doctors moving across the divide to patienthood, and it still does today, though less frequently. Perhaps one of the most powerful testimonies of the difficulty of becoming a practitioner-patient is given by an anonymous doctor (Anonymous 2012). This doctor describes the difficulty they faced in receiving appropriate care, the culture of denial and the stigma which sick doctors are subjected to when unwell. The general practitioner Jonathon Tomlinson reminds us that for years doctors have written about their experiences as patients, hoping others might learn from them and from the realisation that medical education and clinical practice have prepared them so poorly to be patients. His work exploring the experiences of sick healthcare professionals has identified problems relating to, for example: hearing the practitioner-patient's voice; the need for the sick doctor to be seen as a person, not a doctor; the poor standards of care experienced by sick doctors; loss of professional identity; and shame and stigma (Tomlinson 2014). Many of these issues were identified as being implicated in the suicide of a young psychiatrist, Dr Daksha Emson. Dr Emson suffered from recurrent bipolar disorder and, following the birth of her baby, developed a severe depressive illness. She stabbed the 3-month old infant, then poured accelerant over them both and set it alight. Both mother and baby died. In the subsequent inquiry into their deaths the problems of doctors seeking care - of being treated differently from non-medics (for example, to retain confidentiality, information was not passed between the various carers) and the stigma doctors suffer from the NHS when mentally unwell, were all brought to the fore (North East London Strategic Health Authority 2003).

\section{Independent self-help and support groups}

Obtaining the views of mentally ill doctors can be difficult, as even the act of bringing sick health professionals together exposes them to risk. For example, doctors risk their career if their illness is related to an illegal activity such as drug addiction, and even when anonymity is offered there is still a reluctance to share experiences. This can be overcome by using third parties such as the Sick Doctors Trust (http://sick-doctors-trust.co.uk), an independent self-help organisation established in 
MCO answers

1 a 2 b 3 c 4 b 5 a
1996 by a group of doctors recovering from addictions. It helps doctors to access treatment for their problems and allows them the space to give their own personal experiences of being a doctor with an addiction. The Doctors' Support Network (DSN) also gives sick doctors are collective voice. The DSN is a confidential, peer support group for doctors and medical students with mental health concerns, including stress, burnout, anxiety, depression, bipolar disorder, psychoses and eating disorders (www.dsn.org.uk). Perhaps some of the most silent of all distressed doctors are those who have been suspended from work, either due to illness or because of disciplinary or investigative processes. These doctors are often excluded from their professional group - both metaphorically, as they cannot work and feel so shamed by their suspension, but also literally, as many suspended doctors are banned from entering their workplace until the suspension is lifted. The Doctors' Support Group provides a space for doctors who are facing suspension, exclusion, investigation of complaints and/or allegations of professional misconduct to gain support and also to lobby for change (https://doctorssupportgroup.com).

\section{Conclusions and looking to the future}

Doctors can be, and often are, patients. As with all patients receiving care, it is vital that their voice is heard. This is especially important in helping to overcome some of the significant barriers that doctors experience in seeking care. These barriers, as described, are created through a complex interaction of personal, professional and institutional factors and are related to what doctors expect of themselves and what the public expects of doctors.

Doctors have been described as invisible patients and by listening to their voices will they then become visible. This is essential because, as with any other patients, hearing the patient voice makes it possible to put changes in place to improve the responsiveness and appropriateness of services. For sick doctors, these changes might mean ensuring that they have access to confidential care - ideally, not from a colleague or peer unless through their choosing - where their dignity is preserved and where they are not shamed or admonished for becoming unwell. It is important that doctors and other health professionals are competent in treating doctors. Doctors are a vital part of the medical workforce and it is time what we treat those in the profession who become unwell with the same compassion as we expect these doctors to show to their own patients.

\section{References}

Adshead G, Gerada C, Black M (2010) Disruptive and Distressed Doctors: Relevance of Personality Disorder. Annual Conference of European Association for Physician Health, Barcelona 2010. EAPH.

Anonymous (2012) Medicine and mental illness: how can the obstacles sick doctors face be overcome? Psychiatrist, 36: 104-7.

Ballatt J, Campling P (2011) Intelligent Kindness: Reforming the Culture of Healthcare. RCPsych.

Brooks SK, Gerada C, Chalder T (2011) Review of literature on the mental health of doctors: are specialist services needed? Journal of Mental Health, 20: 146-56.

Brooks SK, Gerada C. Chalder T (2013) Doctors and dentists with mental ill health and addictions: outcomes of treatment from the Practitioner Health Programme. Journal of Mental Health, 22: 237-45.

Brooks SK, Gerada C, Chalder T (2017) The specific needs of doctors with mental health problems: qualitative analysis of doctor-patients' experiences with the Practitioner Health Programme. Journal of Mental Health, 26: 161-6.

Dinos S, Stevens S, Serfaty M, et al (2004) Stigma: the feelings and experiences of 46 people with mental illness. Qualitative study. British Journal of Psychiatry, 184: 176-81.

Gabbard GO (1985) The role of compulsiveness in the normal physician. JAMA, 254: 2926-9.

General Medical Council (2013) Good Medical Practice. GMC

Gerada C (2016) Healing doctors through groups: creating time to reflect together. British Journal of General Practice, 66: e776-8.

Henderson M, Brooks SK, del Busso L, et al (2012) Shame! Self-stigmatisation as an obstacle to sick doctors returning to work: a qualitative study. BMJ Open, 2: e001776.

Hinshaw SP, Stier A (2008) Stigma as related to mental disorders. Annual Review of Clinical Psychology, 4: 367-93.

Klitzman R (2008) When Doctors Become Patients. Oxford University Press.

Lelliott P, Tulloch S, Boardman J, et al (2008) Mental Health and Work. Commissioned by the Cross Government Health Work and Well-Being Programme. Royal College of Psychiatrists.

Main T (1975) Some psychodynamics of large groups. In The Large Group: Dynamics and Therapy (ed L Kreeger): 57-86. Routledge.

Menzies-Lyth I (1959) The functions of social systems as a defence against anxiety: a report on a study of the nursing service of a general hospital. Human Relations, 13: 95-121.

North East London Strategic Health Authority (2003) Report of an Independent Inquiry into the Care and Treatment of Daksha Emson and her Daughter Freya. NELSHA.

Parsons $T$ (1951) IIIness and the role of the physician: a sociological perspective. American Journal of Orthopsychiatry, 21: 452-60.

Parveen N (2016) GP found dead after being suspended over bipolar disorder blog. The Guardian, 26 August.

Tomlinson J (2014) Lessons from "the other side": teaching and learning from doctors' illness narratives. BMJ Careers, 2 June.

Wessely A, Gerada C (2013) When doctors need treatment: an anthropological approach to why doctors make bad patients. BMJ Careers, 12 November.

Wrate $R$ (1999) Increase in staff numbers may reduce doctors' 'presenteeism'. BMJ, 319: 1502 
MCOs

Select the single best option for each question stem

1 With respect to doctors and mental illness:

a doctors have high rates of mental illness compared with other professional groups

b only younger doctors have higher rates of mental illness

c female doctors are particularly at risk of depression compared with male doctors

d it is unusual for doctors to suffer from mental illness

e doctors' high 10 protects them from ever becoming mentally ill.

2 When doctors access mental health services for their own needs:

a they find it easy to present to their own general practitioner and ask for help

b it is often difficult for them to receive confidential help c other doctors find it easy to manage these fellow healthcare professionals

$\mathrm{d}$ they have high rate of sick leave compared with other healthcare professionals

e they usually wait until they are completely better before returning to work.

3 Risk factors for doctors developing mental illness include:

a high pay

b low-status job

c personality factors such as perfectionism

d cohesive team working

e working part time.

4 With respect to doctors:

a doctors with mental illness are often seen sympathetically by their own profession

b sick healthcare professionals often blame themselves for their illness c all mental illness in doctors must be referred to the General Medical Council

$d$ trainees must inform their trainer if they develop any form of mental illness

e doctors who are addicted to alcohol must stop work.

5 With respect to mentally ill doctors:

a doctors are often blind to mental illness in their peers

b once in treatment, doctors with mental illness have poor outcomes in terms of return to work

c once in treatment, doctors with drug and/or alcohol addiction generally have poor prognosis

d doctors find it easy to become patients

e shared decision-making is especially important when treating sick healthcare professionals. 